\title{
Estressores e coping: enfermeiros de uma unidade de emergência hospitalar ${ }^{1}$
}

\author{
Stressors and coping: nurses of an unit of hospital emergency
}

\author{
Estresores y coping: enfermeros de una unidad de emergencia hospitalar
}

\author{
Miriane Melo Silveira ${ }^{\mathrm{I}}$, Eniva Miladi Fernandes Stumm ${ }^{\mathrm{II}}$, Rosane Maria Kirchner ${ }^{\mathrm{III}}$
}

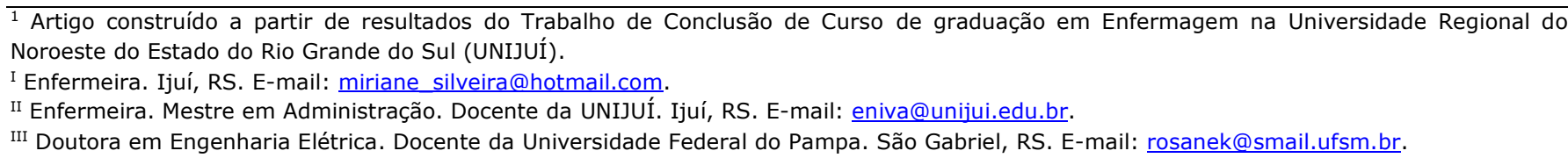

\section{RESUMO}

O trabalho em Emergência é estressante, daí a importância de estratégias de coping para manutenção da saúde e qualidade da assistência. O estudo busca identificar estressores vivenciados por enfermeiros que atuam em uma Emergência de um hospital geral, mecanismos de coping, bem como repercussões na assistência. Pesquisa transversal, quantitativa, analítica, na Emergência do Hospital Mãe de Deus, em Porto Alegre/RS, em 2007, com 19 enfermeiros. Os instrumentos de coleta de dados foram "Inventário de Estresse em Enfermeiros", duas questões abertas e dados sociodemográficos. Maioria é mulher, especialista, 30-45 anos, 47,4\% possuem filhos, 47\% atuam de 10-15 anos na profissão e 68\% trabalham com exclusividade. Eles convivem com inúmeros estressores, a análise das categorias do IEE mostra pequena variabilidade nos escores. Quanto às interferências dos estressores na assistência, destacam-se: demanda, afastamento da assistência, urgência de tempo, dentre outras. Quanto ao coping, são classificadas em estratégias no trabalho e fora dele. As primeiras incluem diálogo, empatia, ajuda mútua e resolução de conflitos. As estratégias fora do trabalho incluem lazer, meditação, relaxamento, estar com a família e valorizar a vida. O gerenciamento do estresse ocupacional pode repercutir em melhora do desempenho dos enfermeiros, com preservação da saúde e ampliação da qualidade da assistência.

Descritores: Estresse; Enfermeiros; Serviço Hospitalar de Emergência.

\section{ABSTRACT}

The work in emergencies is stressful, hence the importance of coping strategies to maintain health and quality of care. The study seeks to identify stressors experienced by nurses who work in an emergency to a general hospital, coping mechanisms and implications for assistance. Search cross-sectional quantitative, analytical, at Emergency Hospital of Mother of God, in Porto Alegre / RS, in 2007, with 19 nurses. The instruments for data collection were "Inventory of Stress on Nurses', two open questions and sociodemographic data. Majorities are women, especially, 30-45 years old, $47.4 \%$ have children, $47 \%$ work for $10-15$ years in the profession and $68 \%$ work exclusively. They live with many stressors; the analysis of categories of IEE shows little variability in scores. As for the interference of stressors in the audience, are: demand, remote assistance, urgency of time, among others. As for coping, are classified into strategies at work and outside. The former include dialogue, empathy, mutual aid and conflict resolution. Strategies outside work include leisure, meditation, relaxation, being with the family and enhance their lives. The management of occupational stress may reflect improvement in the performance of nurses in preserving health and extending the quality of care.

Descriptors: Stress; Nurses; Emergency Service, Hospital.

\section{RESUMEN}

El trabajo en emergencia es de tensión, de ahí la importancia de estrategias de afrontamiento para mantener la salud y la calidad de la atención. El estudio identifica los factores de estrés por las enfermeras que trabajan en emergencia en un hospital general, mecanismos de adaptación y las consecuencias para la asistencia. Pesquisa transversal, cuantitativa, de análisis, en la emergencia en un Hospital en Porto Alegre / RS, en 2007, con 19 enfermeras. Los instrumentos para la recogida de datos fueron "Inventario de Estrés en enfermería", dos preguntas abiertas y datos sociodemográficos. La mayoría son mujeres, especialistas, 30-45 años, 47,4\% tienen hijos, 47\% actúan hace 10-15 años en la profesión y $68 \%$ trabajan con exclusividad. El análisis de IEE muestra poca variabilidad en las puntuaciones. En cuanto la injerencia del estrés en la atención, destacan: demanda, alejamiento de la asistencia, urgencia de tiempo, entre otros. Cuanto al "coping", son clasificadas en estrategias en el trabajo y fuera de ello. Las primeras incluyen diálogo, empatía, ayuda mutua y resolución de conflictos. Fuera de trabajo: ocio, meditación, relajación, estar con familia y valorizar sus vidas. La gestión de estrés puede reflejar la mejora en el desempeño, preservación de la salud y ampliación de la calidad de la atención.

Descriptores: Estrés; Enfermeros; Servicio de Urgencia en Hospital. 


\section{INTRODUÇÃO}

Trabalhar se constitui em um conjunto de atividades impregnadas de valores, comportamentos, representações e intencionalidades. O trabalho é responsável por diferentes graus de motivação e satisfação, principalmente quanto à forma e ao meio no qual ele é desenvolvido e, na medida em que o indivíduo se insere no contexto organizacional, está sujeito a variáveis que afetam diretamente as suas atividades $^{(1)}$.

Dentre as funções dos profissionais da saúde destacam-se as relações contínuas com o outro, que podem influenciar o estilo de vida de quem cuida, bem como serem avaliadas como desgastantes. As características do enfermeiro, enquanto profissão é associada a um trabalho fortemente normatizado, fragmentado, devido à divisão das tarefas e técnicas, com um sistema de turnos (rotatividade), além da excessiva responsabilidade e da necessidade de ampliação de conhecimentos técnicos e tecnológicos ${ }^{(2)}$.

A atuação do enfermeiro em Unidade de Emergência é, conforme diversos estudos, avaliada como desencadeadora de estresse e de desgaste físico e emocional. Ainda que o exercício da enfermagem requeira boa saúde física e mental, raramente os enfermeiros recebem a proteção social adequada. $O$ estresse no trabalho deste profissional não é um fenômeno novo, existem diversas doenças relacionadas ao mesmo(3).

A opção por estudar o estresse do enfermeiro se dá pelo fato de esta profissão ser reconhecida por vários autores ${ }^{(4-5)}$ como estressante, aliado ao conhecimento de que a subjetividade influencia, tanto na percepção, quanto nas respostas do indivíduo ao estresse. Estudar a manifestação do estresse ocupacional entre enfermeiros permite compreender e elucidar alguns problemas, tais como insatisfação profissional, falta de produtividade no trabalho, absenteísmo, acidentes de trabalho e algumas doenças ocupacionais, além de favorecer a proposição de intervenções e busca de soluções ${ }^{(3)}$.

Considerando que à enfermagem compete cuidar, torna-se importante lançar um olhar aliado a ações direcionadas ao cuidado desses profissionais, no sentido de promoção da saúde e melhora do desempenho profissional. Em uma Unidade de Emergência o enfermeiro convive diariamente com situações imprevisíveis, as quais envolvem sofrimento, dor e morte e podem contribuir para o estresse, com repercussões tanto na sua saúde quanto na assistência aos usuários que acessam a referida unidade ${ }^{(6)}$.

O estresse é uma reação bioquímica, normal do organismo, quando o indivíduo se depara com uma situação estressora e, principalmente, significa a tentativa do mesmo em retornar à normalidade ${ }^{(7)}$. 0 que lesa a pessoa e contribui para o surgimento de doenças é viver permanentemente sob tensão e estresse, sofrer o efeito acumulativo do mesmo. Já, o estresse ocupacional é determinado pela percepção que o trabalhador tem das demandas no trabalho e por sua habilidade para enfrentá-las. Daí a relevância de se conhecer mais sobre o estresse no trabalho, visando elencar estratégias para um enfrentamento eficaz dos problemas dele oriundos(5). Dentre as teorias de enfrentamento, uma é a de coping, compreendendo um conjunto de estratégias de enfrentamento a problemas que podem ajudar a pessoa a lidar com eventos estressantes, tanto internos quanto externos(2).

O presente estudo busca identificar estressores vivenciados por enfermeiros que atuam em uma Unidade de Emergência de um hospital geral, mecanismos de coping para lidar com o estresse no trabalho, bem como as repercussões na assistência ao usuário. Os resultados podem contribuir com profissionais da saúde que atuam no âmbito hospitalar, possibilitando refletirem sobre ações na gestão dos estressores, que vão desde a minimização e/ou a utilização de mecanismos de enfrentamento eficazes, repercutindo em melhora do desempenho do trabalhador, com preservação de sua saúde e ampliação da qualidade da assistência aos usuários.

\section{METODOLOGIA}

A pesquisa é de caráter transversal, quantitativo e analítico, realizada na Unidade de Emergência do Hospital Mãe de Deus (HMD), em Porto Alegre/RS. Trata-se de uma organização que conta com infraestrutura apta para receber usuários em situações de urgência e/ou emergência e o modo de atenção aos mesmos é de forma a garantir o melhor atendimento. A média de atendimentos mensal é de 3550 usuários. Integra a equipe de enfermagem da referida instituição 20 enfermeiros e 40 técnicos em enfermagem.

A população do estudo compreendeu todos os enfermeiros que atuam na respectiva unidade. Destes, apenas um não participou, por estar em férias, totalizando 19 profissionais. Os instrumentos utilizados na coleta dos dados foi o "Inventário de Estresse em Enfermeiros"(IEE)(3), acrescido de duas questões abertas, uma referente às opiniões dos enfermeiros quanto às interferências dos estressores na assistência aos usuários e outra relacionada aos mecanismos de enfrentamento utilizados por eles para lidar com o estresse no trabalho. Além destes, foi utilizado um instrumento contendo dados sociodemográficos.

A coleta de dados foi realizada no período de 09 a 30 de agosto de 2007, logo após a aprovação do projeto de pesquisa pela Direção e pelo Comitê de Ética do HMD, sob o parecer consubstanciado $n^{0}$ 
180/07. Foram observados todos os preceitos éticos que regem uma pesquisa com pessoas.

No momento da distribuição dos instrumentos aos enfermeiros, foi realizada breve explanação sobre a pesquisa, destacando objetivos, garantindo segurança quanto à preservação da identidade dos mesmos e orientando em relação à devolução dos instrumentos devidamente preenchidos. Buscou-se reunir os enfermeiros em horários previamente acordados e um fato que chamou a atenção foi a receptividade deles em participar da pesquisa.

Os dados foram analisados com o software estatístico SPSS 7.5 e apresentados em tabelas e um gráfico. Na análise do IEE foram considerados os itens previstos para cada categoria(3). O mesmo apresenta seis categorias para os estressores do ambiente de trabalho: fatores intrínsecos ao trabalho, papéis estressores, relações no trabalho, desenvolvimento na carreira, estrutura e cultura organizacional e interface trabalho-casa. Para avaliar os resultados relativos aos estressores foram considerados os valores da escala de respostas num intervalo de 1 a 5, sendo 1 (nunca), 2 (raramente), 3 (algumas vezes), 4 (muitas vezes) e 5 (sempre). Foram considerados os escores de cada fator para todos os enfermeiros.

\section{RESULTADOS E DISCUSSÃO DOS DADOS}

Considera-se importante, para melhor situar o leitor, caracterizar os enfermeiros pesquisados. A maioria $(78,9 \%)$ é do sexo feminino, $63,3 \%$ com idade entre $30-45$ anos, $31,6 \%, 25-30$ anos e 5,3\%, 45-50 anos; $52,6 \%$ são solteiros, $42,1 \%$ casados, $5,3 \%$ separados e $47,4 \%$ possuem filhos; $73,7 \%$ são especialistas e $26,3 \%$ graduados. No que tange ao tempo de atuação profissional, 47\% atuam de 10-15 anos na profissão, sendo que de 1-5 anos e de 15-20 anos, os percentuais são idênticos $(15,85 \%)$, como também há menos de 1 ano e de 5-10 anos (10,5\%).

Quanto ao tempo de atuação dos enfermeiros no HMD, 52,6\% atuam de 4-10 anos e, em percentuais diferentes, menos de 1 ano, 21,1\% e de 1-4 anos, $26,3 \%$ e em relação a dedicação, $68 \%$ deles trabalham com exclusividade para o HMD, os demais possuem outro vínculo empregatício e a maioria (84\%) optou em desenvolver suas atividades profissionais na referida instituição de saúde.

As respostas dos enfermeiros referentes à utilização do tempo fora do contexto laboral compreendem leituras, estudos e pesquisas, respectivamente, com $63,2 \%$ e $78,9 \%$, afazeres domésticos e atividades físicas, ambos com percentuais de $56,2 \%$.

A seguir são apresentados os resultados obtidos com o uso do IEE, submetidos a tratamento estatístico. Os dados contidos na Tabela 1, a seguir, mostram a freqüência com que os enfermeiros sentem cada ação relacionada aos estressores intrínsecos ao trabalho.

Tabela 1: Ações relacionadas aos "Fatores Intrínsecos ao Trabalho"-IEE, Unidade de Emergência do Hospital Mãe de Deus(HMD), Porto Alegre/RS-2007.

\begin{tabular}{cccccc}
\hline Afirmações & Nunca & Raramente & $\begin{array}{c}\text { Algumas } \\
\text { vezes } \\
\mathbf{n}(\%)\end{array}$ & $\begin{array}{c}\text { Muitas } \\
\text { vezes } \\
\mathbf{n}(\%)\end{array}$ & $\begin{array}{c}\text { Sempre } \\
\mathbf{n}(\%)\end{array}$ \\
\hline Fazer esforço físico para cumprir o trabalho & $5(26,3)$ & $5(26,3)$ & $6(31,6)$ & $2(10,5)$ & $1(5,3)$ \\
Desenvolver atividades além da minha & $3(15,8)$ & $1(5,3)$ & $10(52,6)$ & $3(15,8)$ & $2(10,5)$ \\
função ocupacional & $3(15,8)$ & $3(15,8)$ & $9(47,4)$ & $1(5,3)$ & $3(15,8)$ \\
Cumprir na prática uma carga horária maior & $3(26,3)$ & $9(47,4)$ & $3(15,8)$ & $1(5,3)$ & $1(5,3)$ \\
Levar serviço para fazer em casa & $5(26)$ & $6(31,6)$ & $3(15,8)$ & $1(5,3)$ & - \\
Falta de material necessário ao trabalho & $9(47,4)$ & $6(5,6)$ & $2(10,5)$ & $1(5,3)$ \\
Falta de recursos humanos & $4(21,1)$ & $5(26,3)$ & $7(36,8)$ & $3(15,8)$ & - \\
Trabalhar em instalações físicas inadequadas & $6(31,6)$ & $6(31,6)$ & $4(21,1)$ & $1(5,3)$ & $1(5,3)$ \\
Trabalhar em horário noturno & $3(15,8)$ & $5(26,3)$ & $9(47,4)$ & $1(5)$ \\
Trabalhar em ambiente insalubre & $4(21,1)$ & $8(42,1)$ & $4(21,1)$ & $2(10,5)$ & $1(5,3)$ \\
Executar procedimentos rápidos & $5(26,3)$ & $10(52,6)$ & $3(15,8)$ & - & $1(5,3)$ \\
Receber este salário & $3(15,8)$ & $6(31,6)$ & $5(26,3)$ & $3(15,8)$ & $2(10,5)$ \\
\hline
\end{tabular}

O esforço físico para atuar na unidade pesquisada é mencionado por $52,6 \%$ dos enfermeiros como fator que raramente ou nunca ocasiona estresse, para $31,6 \%$ algumas vezes e para $15,8 \%$ muitas vezes ou sempre é estressante. Esse dado é merecedor de atenção do gestor e dos enfermeiros da respectiva unidade, no sentido de avaliar as condições em que o trabalho é realizado, buscando alternativas conjuntas para minimizá-las. Pesquisa(8) em uma Unidade de Terapia Intensiva (UTI) de um hospital universitário, com 68 trabalhadores onde 30 deles eram enfermeiros, o esforço físico foi considerado como lesão corporal para $46 \%$ dos trabalhadores e se constituiu em um dos principais riscos ocupacionais.

Os trabalhadores de enfermagem em unidades de emergência desenvolvem inúmeras atividades que exigem esforço físico, incluindo o manuseio do 
paciente, retirada e colocação de monitores em prateleiras, deslocamento de equipamentos, transferência de pacientes para outras unidades do hospital, entre outros.

Analisando o item desenvolver atividades além da função ocupacional, $52,6 \%$ algumas vezes e $26,3 \%$ muitas vezes ou sempre sentem como estressante. Este resultado é preocupante, mostra que os enfermeiros estão desenvolvendo atividades que vão além de suas atribuições. Outro fator sentido como estressante por $47,4 \%$ deles algumas vezes, é trabalhar além da carga horária; $21,1 \%$ muitas vezes ou sempre e, os demais, nunca ou raramente sentem. Já, levar serviço para casa, não é sentido por $73,7 \%$ dos enfermeiros como estressante, porém o é algumas vezes, para $15,8 \%$ deles e muitas vezes ou sempre para $10,6 \%$.

Contribuindo na elucidação destas questões, a sobrecarga exigida dos enfermeiros, mais esforço físico para a realização de tarefas e, muitas vezes de outros profissionais, aliada a diversidade das mesmas, tem efeito significativo no trabalho( ${ }^{(9)}$. A demanda de atividades gera novos estímulos, contribuindo para o surgimento de estressores. Uma pesquisa realizada pelo autor envolvendo 68 profissionais em centros cirúrgicos de sete hospitais públicos de Recife/PE mostrou que desenvolver atividades além da função ocupacional, foi avaliado como estressante para $50 \%$ dos pesquisados e cumprir uma carga horária maior, para $43 \%$.

As respostas da maioria dos enfermeiros referentes a falta de materiais para a execução das suas atividades, demonstra que eles não sentem este fator como estressor. Este dado é positivo, mostra que a unidade é provida de materiais para o bom andamento das atividades. Associando-se o item falta de recursos humanos, para $47,4 \%$ deles raramente ou nunca esse fator é estressor, porém para $36,8 \%$ o é somente algumas vezes e para $15,8 \%$ muitas vezes ou sempre. A precariedade de profissionais leva à queda da qualidade da assistência. Assim, na análise do quadro pessoal de enfermagem em uma Unidade de Emergência, torna-se importante considerar a eficácia do serviço, reunindo quantidade e competência técnica ${ }^{(9)}$.

Outro dado que chama a atenção diz respeito ao sentimento dos enfermeiros referente ao trabalho em instalações físicas inadequadas como estressante presente em $21,1 \%$ das respostas, algumas vezes $e$ por $15,8 \%$ muitas vezes. Esses dados igualmente são merecedores de análise dos gestores da unidade pesquisada, cientes de que o ambiente físico interfere na saúde do trabalhador. As condições de trabalho, a motivação e, em conseqüência, o bem-estar dos profissionais de saúde, tem sido relegados a segundo plano ou negligenciado. Atualmente, evidencia-se que poucos hospitais apresentam boas condições de trabalho(10).

Analisando as respostas dos enfermeiros referentes a trabalhar à noite, para $42,1 \%$ deles raramente ou nunca é estressante e para um percentual aproximado $(47,4 \%)$ somente algumas vezes o é; os demais $(10,6 \%)$ muitas vezes ou sempre sentem esta ação como um estressor. Em uma pesquisa(11) com enfermeiros do SAMU, Porto Alegre/RS, na qual também foi utilizado o IEE, para a maioria deles trabalhar em horário noturno não foi sentido como estressor.

A execução de procedimentos rápidos não é mencionada por $78,9 \%$ dos enfermeiros pesquisados como um estressor. Este dado demonstra que os profissionais estão tecnicamente preparados para atuar na respectiva unidade, comprovado pelo tempo de atuação, pela opção por atuarem em emergência, pela qualificação, aspectos esses abordados na caracterização deles.

Considerando as respostas dos enfermeiros referentes a questão salarial, $26,3 \%$ deles somente algumas vezes sentem como estressor, porém $26,3 \%$, muitas vezes ou sempre o sentem como tal. A atual crise no setor saúde repercute no ambiente de trabalho, reduzindo a capacidade das organizações em remunerar os profissionais adequadamente. As pessoas esperam que seus empregos thes proporcionem recompensa material, dinheiro, prestígio e segurança, mas, ultimamente, inúmeras organizações proporcionam aos trabalhadores resultados monetários aquém do almejado, mesmo quando a carga horária é aumentada(12).

Os estressores nas relações de trabalho, apresentados na Tabela 2, a seguir, dizem respeito, principalmente, ao trabalho com pessoas. 0 atendimento a usuários em situação de emergência pode ser percebido pelos enfermeiros como estressante, considerando que é uma área de atuação com elevada exigência em termos de performance.

Analisando a afirmativa começar uma função nova, a mesma é sentida por $57,9 \%$ dos enfermeiros algumas vezes como estressante, $15,8 \%$ muitas vezes e para $26,3 \%$ deles, nunca ou raramente. Importante ressaltar que as mudanças são uma constante no mundo do trabalho e o enfermeiro deve estar apto para atuar neste ambiente, daí a importância do gestor trabalhar com a sua equipe, no sentido de prepará-la para o novo. 
Tabela 2: Ações relacionadas aos estressores nas "Relações no Trabalho"-IEE, Unidade de Emergência do Hospital Mãe de Deus(HMD), Porto Alegre/RS-2007.

\begin{tabular}{|c|c|c|c|c|c|}
\hline Afirmações & $\begin{array}{l}\text { Nunca } \\
\text { n (\%) }\end{array}$ & $\begin{array}{c}\text { Raramente } \\
\text { n (\%) }\end{array}$ & $\begin{array}{c}\text { Algumas } \\
\text { vezes } \\
\text { n(\%) }\end{array}$ & $\begin{array}{l}\text { Muitas } \\
\text { vezes } \\
\text { n }(\%)\end{array}$ & $\begin{array}{c}\text { Sempre } \\
\text { n (\%) }\end{array}$ \\
\hline Começar em uma função nova & $2(10,5)$ & $3(15,8)$ & $11(57,9)$ & $3(15,8)$ & 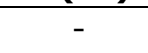 \\
\hline $\begin{array}{c}\text { Conciliar questões profissionais com } \\
\text { familiares }\end{array}$ & $2(10,5)$ & $6(31,6)$ & $6(31,6)$ & $2(10,5)$ & $3(15,8)$ \\
\hline Trabalhar com pessoas despreparadas & $1(5,3)$ & $8(42,1)$ & $9(47,4)$ & $1(5,3)$ & - \\
\hline Relacionamento com colegas enfermeiros & $4(21,1)$ & $7(36,8)$ & $6(31,6)$ & $2(10,5)$ & - \\
\hline Relacionamento com equipe médica & - & $10(52,6)$ & $5(26,3)$ & $3(15,8)$ & $1(5,3)$ \\
\hline Relacionamento com a chefia & $7(36,8)$ & $6(31,6)$ & $4(21,1)$ & $1(5,3)$ & $1(5,3)$ \\
\hline Trabalhar em equipe & $9(47,4)$ & $4(21,1)$ & $4(21,1)$ & $2(10,5)$ & - \\
\hline Prestar assistência a pacientes graves & $6(31,6)$ & $6(31,6)$ & $7(36,8)$ & - & - \\
\hline Atender familiares de pacientes & - & $5(26,3)$ & $9(47,4)$ & $5(26,3)$ & - \\
\hline Ensinar o aluno & $5(26,3)$ & $10(52,6)$ & $3(15,8)$ & $1(5,3)$ & - \\
\hline Atender um número grande de pessoas & - & $2(10,5)$ & $10(52,6)$ & $4(21,1)$ & $3(15,8)$ \\
\hline
\end{tabular}

Conciliar questões vivenciadas no ambiente laboral com as do lar, para $26,3 \%$ dos enfermeiros, muitas vezes ou sempre, e para $31,6 \%$ algumas vezes é estressante. Em se tratando de uma população predominantemente feminina, esse resultado é compreensível, pois a singularidade do trabalho da enfermagem é marcante não somente por esta razão, mas pela especificidade das ações que desenvolvem no dia-a-dia. Elas convivem com a dinâmica das organizações no desenvolvimento de suas atividades e, ao mesmo tempo, gerenciam suas vidas como pessoas, esposas e mães.

No que tange aos sentimentos dos enfermeiros referentes a trabalhar com pessoas despreparadas, $47,4 \%$ deles raramente ou nunca consideram estressante. Um percentual idêntico $(47,4 \%)$ sente que este fato é gerador de estresse somente algumas vezes. Daí a necessidade de se considerar a subjetividade das pessoas e o quanto esta interfere nas respostas e na própria percepção do estresse.

Analisando 0 relacionamento entre os enfermeiros, $57,9 \%$ deles nunca ou raramente sentem esta ação como um estressor, porém $31,6 \%$ deles, algumas vezes sentem e 10,5\% muitas vezes. Contribuindo, as relações entre colegas pode ser fonte potencial de estresse e nocivas para a saúde mental. No entanto, se forem pautadas pela compreensão, tolerância e espírito de auto-ajuda, tais relações podem ser gratificantes e contribuir para um bom ambiente de trabalho(10). Importante destacar que existem conflitos nas relações entre enfermeiros e médicos, pois $26,3 \%$ dos enfermeiros algumas vezes sentem como estressante e $21,1 \%$ muitas vezes ou sempre. Para as autoras ${ }^{(13)}$ o conflito é inerente à relação entre pessoas e não deve ser encarado como negativo. Observa-se, segundo elas, que muitas situações conflitantes que ocorrem são importantes como sinalizadoras de mudanças, oportunizando que sejam repensadas e, posteriormente, modificadas várias formas de agir na Unidade.

O relacionamento com a chefia, para mais da metade dos enfermeiros $(68,4 \%)$ não é estressante, mas para $21,1 \%$ algumas vezes e $10,6 \%$, muitas vezes ou sempre o é. Esse resultado demonstra que a relação entre os pesquisados e a gerência pode ser melhorada. No mundo do trabalho, o superior hierárquico pode ser um ponto de referência para a maior parte das pessoas e se constituir em fonte de recompensas, contribuírem para satisfação, bemestar psicológico ou ser fonte de estresse e de tensão(10).

Quanto a ação de assistir pacientes graves, para $63,2 \%$ nunca ou raramente é estressante, mas para $36,8 \%$ deles algumas vezes é. Pesquisa com enfermeiros que atuam em emergência, apesar de sua pronta e efetiva atuação frente à instabilidade da situação dos pacientes graves, as condições externas a essa situação foram consideradas mais estressantes ${ }^{(14)}$.

Ainda em relação a análise da Tabela 2 , atender um número grande de pessoas, para $10,5 \%$ dos enfermeiros raramente é estressante, mas para mais da metade deles $(52,6 \%)$ algumas vezes e para $36,9 \%$ muitas vezes ou sempre é estressante. No HMD, para mais de $60 \%$ dos pacientes internados a porta de entrada é a Emergência. A racionalização, a mecanização e a burocratização excessiva do trabalho, impedem muitas vezes que o trabalhador desenvolva sua capacidade crítico-criativa, atuando como "desumanizantes", prestando atendimento de forma inadequada, sendo inclusive, percebido pelos clientes, algumas vezes(15). Como há excesso de demanda no atendimento dos hospitais, os enfermeiros não conseguem prestar um atendimento adequado a todos.

$\mathrm{Na}$ Tabela 3, a seguir, é apresentada a freqüência com que os enfermeiros sentem cada uma 
Tabela 3: Ações relacionadas aos "Papéis Estressores da Carreira"-IEE, Unidade de Emergência do Hospital Mãe de Deus(HMD), Porto Alegre/RS-2007.

\begin{tabular}{cccccc}
\hline Afirmações & Nunca & Raramente & $\begin{array}{c}\text { Algumas } \\
\text { vezes } \\
\mathbf{n}(\%)\end{array}$ & $\begin{array}{c}\text { Muitas } \\
\text { vezes } \\
\mathbf{n}(\%)\end{array}$ & $\begin{array}{c}\text { Sempre } \\
\mathbf{n}(\%)\end{array}$ \\
\hline Fazer um trabalho repetitivo & $5(26,3)$ & $5(26,3)$ & $5(26,3)$ & $3(15,8)$ & $1(5,3)$ \\
Sentir desgaste emocional com o trabalho & - & $6(31,6)$ & $8(42,1)$ & $4(21,1)$ & $1(5,3)$ \\
Trabalhar em clima de competitividade & $2(10,5)$ & $3(15,8)$ & $7(36,8)$ & $4(21,1)$ & $3(15,8)$ \\
$\quad$ Prestar assistência ao paciente & $5(26,3)$ & $11(57,9)$ & $2(10,5)$ & $1(5,3)$ & - \\
Distanciamento entre teoria e prática & $4(21,1)$ & $8(42,1)$ & $6(31,6)$ & $1(5,3)$ & - \\
Desenvolver pesquisa & $7(36,8)$ & $6(31,6)$ & $5(26,3)$ & - & $1(5,3)$ \\
Sentir-se impotente diante das tarefas a serem & $4(21,1)$ & $8(42,1)$ & $5(26,3)$ & $1(5,3)$ & $1(5,3)$ \\
$\quad$ realizadas & $6(31,6)$ & $5(26,3)$ & $4(21,1)$ & $3(15,8)$ & $1(5,3)$ \\
Dedicação exclusiva à profissão & $8(42,1)$ & $7(36,8)$ & $2(10,5)$ & $2(10,5)$ & - \\
Indefinição do papel do enfermeiro & $4(21,1)$ & $7(36,8)$ & $5(26,3)$ & $1(5,3)$ & $2(10,5)$ \\
Responsabilizar-se pela qualidade de serviço & & & & & \\
que a Instituição presta & & & & &
\end{tabular}

Evidencia-se que para $21,1 \%$ dos enfermeiros, somando as freqüências muitas vezes ou sempre, realizar trabalho repetitivo se constitui em um estressor no trabalho, bem como para $26,3 \%$ deles, algumas vezes. Neste sentido, quanto maior o número de estímulos novos, mais estressante a situação. Por outro lado, a pouca variedade das tarefas pode estar associada a ansiedade e depressão, como também o trabalho rotineiro e contínuo, durante anos, pode diminuir a flexibilidade das pessoas ${ }^{(13)}$.

O posicionamento dos enfermeiros referente a sentir desgaste emocional com 0 trabalho corresponde a um percentual de $42,1 \%$, na freqüência algumas vezes, $26,4 \%$ muitas vezes ou sempre e para os demais raramente é estressante. 0 ambiente de trabalho deve ser o mais saudável possível, e, em se tratando de trabalhadores da saúde, o fato de lidarem com vidas o tempo todo, os cuidados devem ser redobrados.

Analisando a variável trabalhar em clima de competitividade, $36,8 \%$ dos enfermeiros algumas vezes sentem esta ação como estressante, 36,9\%, muitas vezes ou sempre. A competitividade é marcante no atual contexto social e exacerbada pela competição, impregnada nas relações humanas ${ }^{(9)}$. Segundo o autor, é evidente que essa lógica competitiva divide o mundo em vencedores e perdedores.

Ainda em relação a análise da Tabela 3, quanto ao posicionamento dos enfermeiros referente ao Distanciamento entre teoria e prática, 31,6\% deles algumas vezes sentem a referida ação como estressora, 5,3\% muitas vezes e $63,2 \%$ nunca ou raramente. Ao relacionar as respostas dos enfermeiros aos dados sociodemográficos, $73,7 \%$ deles são especialistas na área, teoricamente, esses percentuais deveriam ser menores. No que tange as instituições de ensino, elas possuem papel importante no sentido de prepará-los, porém cada profissional, permanentemente, deve buscar aprimoramento e crescimento.

Analisando a afirmação Sentir-se impotente diante das tarefas a serem realizadas, para $26,3 \%$ dos enfermeiros algumas vezes gera estresse e para $10,6 \%$ muitas vezes ou sempre. Uma alternativa para minimizar o sofrimento psíquico e o desgaste emocional gerado pelo sofrimento e/ou morte do paciente, é de os enfermeiros contarem com apoio emocional, possibilitando compartilhar angústias e aprender a lidar com elas.

Analisando a afirmação Dedicação exclusiva à profissão, para $57,9 \%$ deles não é estressante, porém para $21,1 \%$ algumas vezes e muitas vezes ou sempre é. O contexto da Saúde no País, muitas vezes obriga os profissionais a buscarem alternativas para complementar a renda familiar. A política vigente, o achatamento dos salários, a restrição do mercado de trabalho e o desemprego, são fatores que dificultam para os profissionais muitas vezes os obrigam a atuar em mais de um local de trabalho, passando a cumprir uma carga horária longa, que compromete sua qualidade de vida. Pesquisa(16) realizada com 37 profissionais de enfermagem de uma unidade de pronto atendimento mostrou que $97 \%$ deles relataram sentirem-se estressados e uma das sugestões para redução do estresse estava relacionada a sobrecarga de trabalho.

Quanto a Indefinição do papel do enfermeiro, $78,9 \%$ nunca ou raramente sentem esta ação como estressante, porém $10,5 \%$ algumas vezes e um percentual idêntico, muitas vezes sentem. Esta é 
uma situação que exige determinação das lideranças de enfermagem. Em uma pesquisa com enfermeiros de centro cirúrgico, o cuidado direto ao paciente era prestado por técnicos e auxiliares de enfermagem ${ }^{(2)}$.
Dando continuidade à análise das categorias que integram o IEE, na sequência é apresentada a Tabela 4 , referente a estrutura e cultura organizacional.

Tabela 4: Ações relacionadas aos estressores "Estrutura e Cultura Organizacional"-IEE, Unidade de Emergência do Hospital Mãe de Deus(HMD), Porto Alegre/RS-2007.

\begin{tabular}{|c|c|c|c|c|c|}
\hline Afirmações & $\begin{array}{l}\text { Nunca } \\
\text { n (\%) }\end{array}$ & $\begin{array}{c}\text { Raramente } \\
\text { n (\%) }\end{array}$ & $\begin{array}{l}\text { Algumas } \\
\text { vezes } \\
\text { n }(\%)\end{array}$ & $\begin{array}{l}\text { Muitas } \\
\text { vezes } \\
\text { n }(\%)\end{array}$ & $\begin{array}{c}\text { Sempre } \\
\text { n (\%) }\end{array}$ \\
\hline Executar tarefas distintas simultaneamente & - & $7(36,8)$ & $9(47,4)$ & $2(10,5)$ & $1(5,3)$ \\
\hline $\begin{array}{l}\text { Resolver imprevistos que acontecem no local } \\
\text { de trabalho }\end{array}$ & $1(5,3)$ & $2(10,5)$ & $12(63,2)$ & $2(10,5)$ & $2(10,5)$ \\
\hline $\begin{array}{c}\text { Responder por mais de uma função neste } \\
\text { emprego }\end{array}$ & $6(31,6)$ & $5(26,3)$ & $5(26,3)$ & $1(5,3)$ & $2(10,5)$ \\
\hline $\begin{array}{l}\text { Administrar ou supervisionar o trabalho de } \\
\text { outras pessoas }\end{array}$ & $4(21,1)$ & $3(15,8)$ & $6(31,6)$ & $3(15,8)$ & $3(15,8)$ \\
\hline Manter-se atualizada & $6(31,6)$ & $3(15,8)$ & $7(36,8)$ & $2(10,5)$ & $1(5,3)$ \\
\hline $\begin{array}{c}\text { Falta de espaço no trabalho para discutir as } \\
\text { experiências, tanto as positivas como as } \\
\text { negativas }\end{array}$ & $3(15,8)$ & $7(36,8)$ & $5(26,3)$ & $4(21,1)$ & 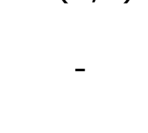 \\
\hline Fazer turnos alternados de trabalho & $6(31,6)$ & $6(31,6)$ & $6(31,6)$ & $1(5,3)$ & - \\
\hline Ter um prazo curto para cumprir ordens & $2(10,5)$ & $6(31,6)$ & $10(52,6)$ & $1(5,3)$ & - \\
\hline Restrição da autonomia profissional & $3(15,8)$ & $5(26,3)$ & $7(36,8)$ & $2(10,5)$ & $2(10,5)$ \\
\hline $\begin{array}{c}\text { Interferência da Política Institucional no } \\
\text { trabalho }\end{array}$ & $4(21,1)$ & $5(26,3)$ & $5(26,3)$ & $3(15,8)$ & $2(10,5)$ \\
\hline A especialidade em que trabalho & $6(31,6)$ & $6(31,6)$ & $5(26,3)$ & $2(10,5)$ & - \\
\hline
\end{tabular}

Quanto as afirmações dos enfermeiros referentes a Executar tarefas distintas simultaneamente, para $36,8 \%$ deles raramente é estressante, mas para $47,7 \%$ algumas vezes e para $15,8 \%$ muitas vezes ou sempre o é. No que tange a Resolver imprevistos que acontecem no local de trabalho, para $15,8 \%$ deles raramente ou nunca é sentido como estressante, mas para $63,2 \%$ algumas vezes e para $21 \%$ muitas vezes ou sempre é estressante. Neste sentido, quanto maior a incerteza, maior a capacidade dela gerar sentimento de ameaça(17). Em uma Unidade de Emergência os profissionais necessitam estar preparados para todo tipo de acontecimento, concomitante a tomadas de decisão rápidas e eficazes.

Aliando-se os posicionamentos dos enfermeiros pesquisados referentes a Responder por mais de uma função neste emprego, para $15,8 \%$ deles muitas vezes ou sempre e $26,3 \%$ algumas vezes gera estresse. Contribuindo(18), há profissionais desmotivados pela sobrecarga de trabalho e por não conseguir cumprir todas as tarefas, ou mesmo de forma rápida, sem tempo para refletir sobre o que está realizando. $O$ profissional sente-se então desprestigiado, sem identidade, apenas mais um num universo de trabalhadores da saúde.

Administrar ou supervisionar o trabalho de outras pessoas, para $31,6 \%$ dos enfermeiros as vezes é sentido como estressante e para mais de $30 \%$ deles muitas vezes ou sempre. Para encontrar o equilíbrio, é importante que tanto a organização quanto os profissionais estejam conscientes dos fatores estressantes que partilham. Para que isso ocorra é necessário que os envolvidos queiram fazer as adaptações necessárias.

Atualmente, a gestão em organizações de saúde envolve não somente os administradores, mas os demais profissionais que assumem o desafio de planejar, organizar, coordenar e direcionar as atividades e as pessoas. Daí a necessidade de o gestor prepará-los, ciente de que o desenvolvimento de uma organização tem relação direta com sua capacidade em desenvolver pessoas.

Nas afirmações dos enfermeiros referentes a manter-se atualizada, $36,8 \%$ deles referem que algumas vezes e $15,8 \%$ muitas vezes ou sempre esta ação é estressante. Na população pesquisada, $47,4 \%$ algumas vezes e $21,1 \%$ muitas vezes sentem falta de espaço no trabalho para discutir experiências, tanto positivas como negativas. Neste sentido, um bom relacionamento interpessoal pode fornecer apoio para o trabalhador enfrentar as situações de desgaste e estresse no seu dia-a-dia.

Para $36,8 \%$ dos enfermeiros a Restrição da autonomia profissional algumas vezes é sentida como estressante e para $21 \%$ muitas vezes ou sempre. Em uma pesquisa ${ }^{(19)}$ com 65 enfermeiros de um hospital de São Paulo, a ausência de reconhecimento da enfermagem como atividade essencial no contexto da assistência à saúde, a falta de autonomia para a 
tomada de decisões e a inadequação da legislação do seu exercício profissional foram os principais estressores. Os profissionais de enfermagem, por serem submetidos a grandes pressões, físicas e psicológicas, potencializam o aparecimento de enfermidades. Desta forma, identificam-se estressores de diversos tipos e integram o universo de atuação da enfermagem, ligados aos aspectos relativos à unidade de atuação, cargos ocupados, satisfação no trabalho e clientela atendida(18).

Quanto a Interferência da Política Institucional no trabalho, 26,3\% dos enfermeiros algumas vezes sentem a referida ação como um estressor e, em igual percentual, muitas vezes. A organização piramidal da instituição hospitalar é responsável pelas pressões que os profissionais de saúde sofrem, excluindo os médicos que, geralmente, não pertencem à instituição e usam o ambiente para suas atividades, levando ao conflito entre comportamento médico e demais profissionais da saúde(20). Concorda-se com a autora quando afirma que o ambiente hospitalar tem mais problemas comportamentais do que técnicos.

A Gráfico 1 permite visualizar, comparativamente, as freqüências com que os enfermeiros sentem os estressores em cada uma das categorias do IEE analisadas e a Tabela 5 apresenta a estatística dos escores dos estressores conforme avaliação dos enfermeiros.

Gráfico 1: Sentimentos dos enfermeiros em cada categoria do IEE, Unidade de Emergência do Hospital Mãe de Deus(HMD), Porto Alegre/RS-2007.

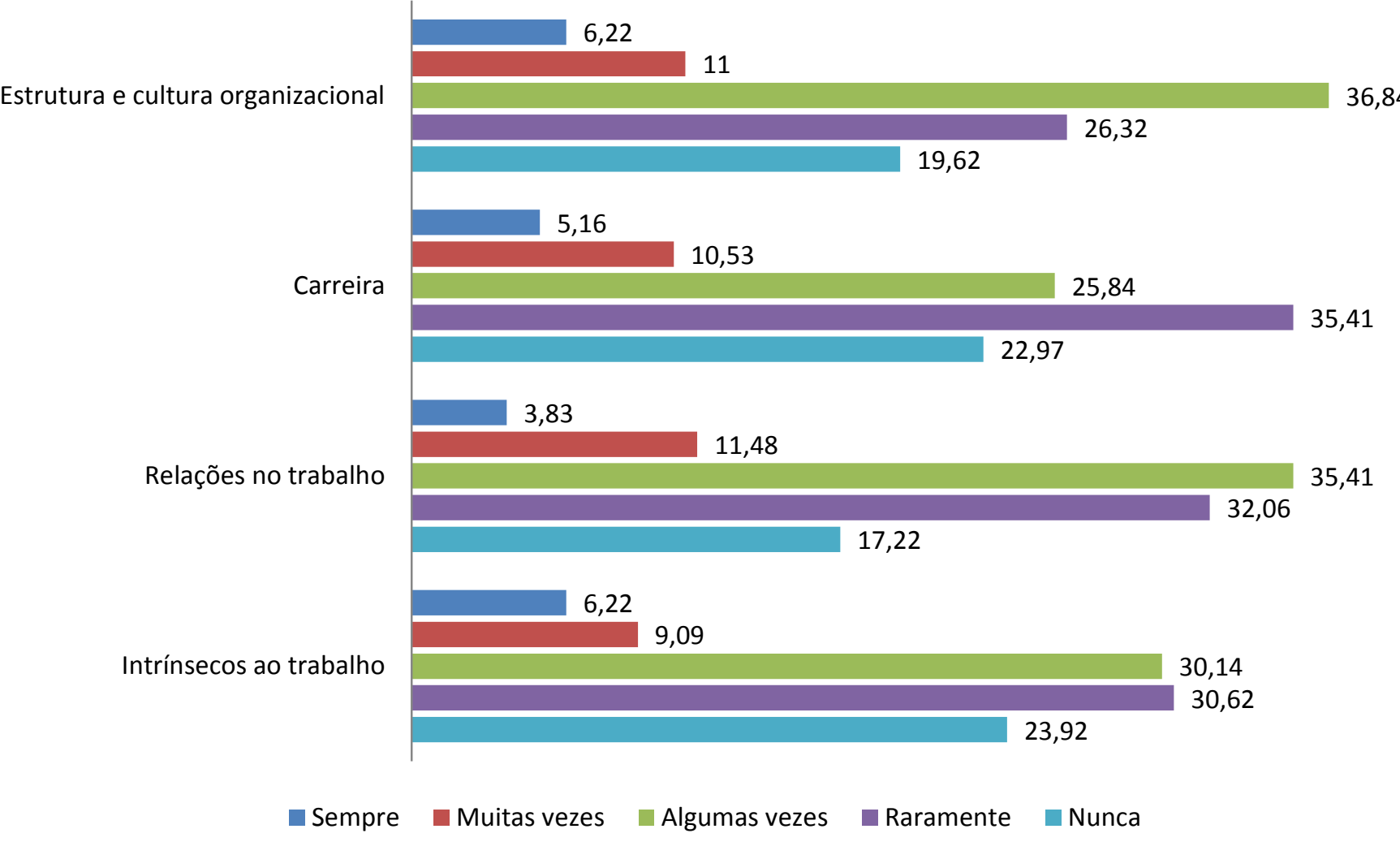

Tabela 5: Estatística descritiva dos escores das categorias do IEE, Unidade de Emergência do Hospital Mãe de Deus(HMD), Porto Alegre/RS-2007.

\begin{tabular}{cccccc}
\hline Categorias do IEE & Li* & Ls** & Média & Desvio Padrão & CV(\%) \\
\hline Fatores intrínsecos ao trabalho & 1 & 5 & 2,43 & 0,37 & 15,09 \\
Relações no trabalho & 1 & 5 & 2,53 & 0,48 & 19,12 \\
Papéis estressores da carreira & 1 & 5 & 2,40 & 0,40 & 16,56 \\
Estrutura e cultura organizacional & 1 & 5 & 2,58 & 0,31 & 12,00 \\
\hline
\end{tabular}

*Li: limite inferior

$* *$ Ls: limite superior

Ao analisar as categorias de forma global, houve pequena variabilidade nos escores (desvio padrão e coeficiente de variação menor que $20 \%$ ). A categoria que obteve maior variabilidade na avaliação dos enfermeiros foi "Relações no trabalho".

As respostas dos 19 enfermeiros que integraram a pesquisa ao questionamento referente a 
interferência dos estressores na assistência ao usuário, estão descritas a seguir, salientando a frequência com que ocorreram (número de enfermeiros): demanda (5), não interferência (3), afastamento da assistência (2), urgência de tempo (2) interferência positiva e negativa (2), tempo insuficiente para a assistência (1), relações enfermeiro $\mathrm{x}$ cliente $\mathrm{x}$ equipe $(1)$, burocracia, prazos (1) assistência por técnicos em enfermagem(1), qualidade da assistência (1), de forma negativa, na atenção e visão do todo "sala", (1) falta de mão-deobra, atestados, férias(1), exposição a agressões verbais e físicas (1), o estresse gerado pelo familiar(1) e a gravidade/complexidade da assistência(1).

Analisando as opiniões emitidas pelos enfermeiros e, ao se reportar as categorias do IEE, vários questionamentos emergem, mas um se destaca: será que a maioria deles optou por negar que os estressores interferem na assistência ou realmente eles pensam desta forma e conseguem fazer com que os mesmos não interfiram? Esses dados podem se constituir em indicativo de outras pesquisas envolvendo a temática, inclusive com novos olhares, utilizando uma abordagem qualitativa e observação participante.

Entende-se por enfrentamento o que a pessoa realmente pensa e sente, e o que faria em determinadas situações. O mesmo é uma estratégia que ela utiliza, não necessariamente consciente, para saber o maior número de informações sobre os acontecimentos e condições psíquicas, visando diminuir as respostas ao estresse e manter o equilíbrio orgânico(16). O referido processo pode modificar-se, dependendo da avaliação e reavaliação do estressor visando a adaptação da pessoa, diminuindo a tensão e restaurando o equilíbrio.

Analisando as estratégias mencionadas pelos enfermeiros pesquisados, optou-se por classificá-las em utilizadas no ambiente de trabalho e fora dele. As estratégias no ambiente de trabalho, de acordo com a frequência com que ocorreram (número de enfermeiros) compreendem: estabelecer e manter diálogo(6), colocar-se no lugar do outro(3), ajuda mútua, de colegas(2), resolver situações conflitantes(2), buscar aperfeiçoamento profissional(1), bom humor, calma, atenção, cordialidade, respeito: funcionários, familiares, pacientes(1), não transmitir ao paciente o estresse vivenciado(1) e assistir o paciente com qualidade técnica e de forma humanizada, resultando em satisfação pessoal(1).

As estratégias utilizadas pelos enfermeiros fora do ambiente de trabalho incluem: atividades de lazer(9), ir ao salão de beleza(1), meditação, relaxamento(5), massagem(1) psicoterapia(1), estar com a família (4), ao sair do hospital, esquecer o que aconteceu no referido ambiente(3), valorizar a vida fora do hospital(2) e dedicar "tempo para si"(1).

A autora(2) destaca quatro processos de coping: $o$ primeiro diz respeito a interação que ocorre entre indivíduos e ambiente; o segundo à função do coping, que é administrar a situação; o terceiro discorre sobre a avaliação cognitiva, como o indivíduo percebe, interpreta um fenômeno e, o quarto e último fala sobre a mobilização de energia que irá despender esforços cognitivos e comportamentais para reduzir, tolerar e/ou minimizar as demandas entre indivíduo e ambiente. Daí a necessidade dos enfermeiros conhecerem mecanismos de enfrentamento ao estresse no trabalho e, a partir daí, poder utilizá-los visando bem-estar e desenvolvimento de suas atividades laborais com prazer.

Os autores(17) explicitam como formas de enfrentamento ao estresse: técnicas de relaxamento, alimentação, exercício físico, repouso, lazer, sono, psicoterapia, autoconhecimento, atividades prazerosas, avaliação da QV, reavaliação do limite de tolerância e exigência, convivência menos conflituosa com pessoas e grupos.

A subjetividade diante de um evento é indispensável na avaliação do mesmo como estressante ou não. A partir daí, a pessoa pode utilizar mecanismos de coping individuais, tais como a obtenção de conhecimentos, horário de lazer e distração, meditação, formas de enfrentamento, entre outros, para atenuar ou até modificar a avaliação proposta, promovendo uma melhoria da qualidade de vida desse profissional(20).

Analisando as colocações dos autores, várias estratégias de enfrentamento ao estresse são utilizadas pelos enfermeiros que integraram esta pesquisa e este é um dado positivo, que, talvez possa responder, em parte, o questionamento feito anteriormente, referente as interferências dos estressores na assistência ao usuário. Pensa-se que se os enfermeiros pesquisados estão utilizando estratégias eficazes aos estressores vivenciados no trabalho, consequentemente, não há repercussões negativas na assistência ao usuário.

\section{CONCLUSÕES}

O estresse é um risco ocupacional para os trabalhadores, daí a relevância de ser reconhecido precocemente. O uso do IEE permite afirmar que os enfermeiros vivenciam inúmeros estressores no trabalho, porém, ao analisar as categorias de forma global, por meio dos escores, incluindo todos os itens que as integram, observa-se pequena variabilidade nos escores (desvio padrão e coeficiente de variação menor que 20\%). Este resultado mostra que os enfermeiros avaliam os estressores no ambiente de trabalho de maneira semelhante. 
Outro aspecto a ser destacado é que o IEE é um instrumento que pode ser utilizado em diferentes regiões do país, como também nas diversas áreas de atuação do enfermeiro, pelo fato de ter sido criado, testado e validado em Brasília/Brasil. Outro dado importante no que tange aos itens que integram cada categoria do IEE, é que vários deles podem se constituir em indicadores de gestão e serem utilizados na respectiva unidade para melhorar a QV dos enfermeiros, com repercussões positivas na assistência aos usuários.

A realização desta pesquisa permite afirmar que na unidade pesquisada os enfermeiros convivem com inúmeros estressores, porém conseguem lidar de maneira adequada, fazendo com que eles não interfiram, significativamente, na assistência ao usuário e, para tanto, utilizam mecanismos de coping eficazes, indo ao encontro da literatura pesquisada. Pensa-se que desta forma eles se mantêm saudáveis, prestam uma boa assistência e contribuem para a manutenção de uma imagem positiva da Organização frente à comunidade.

Os resultados desta pesquisa podem ser utilizados por enfermeiros que atuam tanto em hospitais quanto na Rede Básica de Saúde, com o intuito de refletir sobre o estresse e mobilizar ações visando reduzir os estressores, bem como elencar estratégias de enfrentamento eficazes para lidar com o estresse no trabalho. Os mesmos podem desencadear reflexões de profissionais que atuam em unidades de emergência, bem como instigar pesquisadores para usarem o IEE em diferentes unidades de emergência, em nível regional e/ou estadual, possibilitando inferências.

\section{REFERÊNCIAS}

1. Murofuse NT. O adoecimento dos trabalhadores de enfermagem da Fundação Hospitalar do Estado de Minas Gerais: reflexo das mudanças no mundo do trabalho [thesis]. Ribeirão Preto: Escola de Enfermagem/USP; 2004. 298 p.

2. Guido LA. Stress e coping entre enfermeiros de centro cirúrgico e recuperação anestésica [thesis]. São Paulo: Escola de Enfermagem/USP; 2003.

3. Stacciarini JMR, Trócolli BT. Instrumento para mensurar o estresse ocupacional: inventário de estresse em enfermeiros (IEE). Rev. Latino-am. enfermagem. 2000;8(6):40- 9 .

4. Lauter TL. O desgaste profissional do enfermeiro [thesis]. Salamanca: Universidade Pontifícia de Salamanca; 1995.

5. Stumm EMF. O estresse de equipes de enfermagem que atuam em Unidades de Centro Cirúrgico nos Hospitais da Cidade de Ijuí [dissertation]. Porto Alegre: Programa de Pós Graduação em Administração/UFRGS; 2000.

6. Ritter RS, Stumm EMF, Kirchner RM, Análise de Burnout em profissionais de uma unidade de emergência de um hospital geral. Rev. Eletr. Enf. [Internet]. 2009 [cited 2009 jun 10]; 11(2):236-48. Available from: http://www.fen.ufg.br/revista/v11/n2/v11n2a02.htm

7. Lima EDRP, Carvalho DV. Estresse Ocupacional: Considerações Gerais. Nursing. 2000;3(22):30-4.

8. Nishide VM, Benatti MCC. Riscos ocupacionais entre trabalhadores de enfermagem de uma unidade de terapia intensiva. Rev.Esc.Enf.USP. 2004;38(4):406-14.

9. Aquino JM. Estressores no trabalho das enfermeiros em centro cirúrgico: conseqüências profissionais e pessoais [thesis]. Ribeirão Preto: Escola de Enfermagem de Ribeirão Preto/USP; 2005.

10. Martins MCA. Situações indutoras de stress no trabalho dos enfermeiros em ambiente hospitalar. Millenium-Revista do ISPV [Internet]. 2003 [cited 2009 dez 30];28. Available from: http://www.ipv.pt/millenium/millenium28/18.htm.

11. Costa CFL, Oliveski CC, Deckert D. Estressores vivenciados por enfermeiros de um serviço préhospitalar e estratégias de enfrentamento [monography]. Ijuí: Pós-Graduação em Urgência, Emergência e Trauma/UNIJUI; 2007.

12. Maslach C, Leiter MP. The truth about Burnout: how organization cause, personal stress and what to do about it. San Francisco: Jossey-Bass; 1997.

13. Stumm EMF, Maçalai R, Kirchner RM. Dificuldades enfrentadas por enfermeiros de um Centro Cirúrgico. Texto contexto-enferm. [Internet] 2006 [cited $2009 \mathrm{dez}$ 30];15(3):464-71. Available from: http://www.scielo.br/pdf/tce/v15n3/v15n3a11.pdf.

14. Batista KM, Bianchi ERF. Estresse do enfermeiro em unidade de emergência. Rev Latino-am Enfermagem. 2006;14(4):534-9.

15. Casate JC, Corrêa AK. Humanização do atendimento em saúde: conhecimento veiculado na literatura brasileira de enfermagem. Rev. Latino-Am. Enfermagem. 2005;13(1):105-11.

16. Calderero ARL, MiassoAF, Corradini-Webster CM. Estresse e estratégias de enfrentamento em uma equipe de enfermagem de pronto atendimento. Rev. Eletr. Enf. [Internet] 2008 [cited 2009 mar 10];10(1):52-62. Available from:

http://www.fen.ufg.br/revista/revista/v10/n1/v10n1a 05.htm.

17. França $A C L$, Rodrigues $A L$. Stress e trabalho: uma abordagem psicossomática. São Paulo: Atlas; 2002.

18. Servo MLS. Implantação de um hospital geral Clériston Andrade e caminhar da coordenação: Stress, Coping e Burnout. Revista Sitientibus. 2006;34:7-24.

19. Zorzi GMF, Ribeiro LE, Paes SMJ, Giesbrecht PAC. Comparação entre os níveis de ansiedade e stress apresentados e percebidos pela equipe de enfermagem. Enfermería global [Internet]. 2004 [cited 2009 dez 30];5:1-12. Available from: http://revistas.um.es/eglobal/article/view/540/593.

20. Bianchi ERF. Enfermeiro hospitalar e o stress. Rev.esc. enferm. USP. 2000;34(4):390-4.

Artigo recebido em 26.08.08.

Aprovado para publicação em 25.08.09.

Artigo publicado em 31.12.09. 